\title{
Hello from the other side: Molecular imaging of the right ventricle
}

\author{
Jens Sörensen, $M D, P h D^{a, b}$ \\ a Department of Surgical Sciences, Section for Radiology and Nuclear Medicine, Uppsala \\ University, Uppsala, Sweden \\ b PET-Centre, Uppsala University Hospital, Uppsala, Sweden
}

Received Apr 20, 2020; accepted Apr 20, 2020

doi: $10.1007 / \mathrm{s} 12350-020-02210-4$

\section{See related article, pp. 2784-2795}

For decades, the right heart was to some extent regarded merely as an extension of the venous system. This view was potentially introduced when the invention of the Fontan procedure showed that the right ventricle (RV) could be bypassed and children with univentricular circulation could live relatively normal lives for many years. ${ }^{1}$ Over the last decade, right heart function is increasingly recognized as a key aspect of prognosis in many cardiac disease states emanating from the left side of the heart. ${ }^{2}$ In hindsight, this is not surprising because any condition that increases pulmonary pressures will eventually require the right ventricle to work harder. ${ }^{3} \mathrm{~A}$ recent realization is that $\mathrm{LV}$ pathophysiology does not necessarily translate directly to the $\mathrm{RV}$, and further research is needed. ${ }^{4}$

Radionuclide-based studies focusing on the RV are scarce, but the message from studies in pulmonary hypertension with the most commonly used radiopharmaceuticals is clear: the ratio of $\mathrm{RV} / \mathrm{LV}$ uptake is associated with RV pressures, RV hypertrophy, and prognosis using standard perfusion tracers, ${ }^{5}$ as well as for FDG-PET. ${ }^{6-8}$ However, the RV is less relevant in subjects with suspected CAD and no history or signs of heart failure, accounting for the vast majority of patients encountered by nuclear cardiologists. In addition, RV uptake and RV/LV-ratios are affected by scanner resolution and image reconstruction, the impact of which has

\footnotetext{
Reprint requests: Jens Sörensen, MD, PhD, PET-Centre, Uppsala University Hospital, Entrance 86, 75185 Uppsala, Sweden; jens.sorensen@pet.uu.se

J Nucl Cardiol 2021;28:2796-8.

$1071-3581 / \$ 34.00$

Copyright (C) 2020 American Society of Nuclear Cardiology.
}

not been well studied. As a consequence, most commercial software packages do not calculate RV or RV/ LV uptake data. Recent guidelines on cardiac radionuclide imaging acknowledge the existence of the right ventricle, ${ }^{9,10}$ and most practitioners are aware of the science, but left with qualitative assessments based on visual inspection it is not easy to integrate RV pathology into the report.

There are a range of opportunities for current nuclear cardiology technologies to contribute in the evaluation of RV function in heart failure. ${ }^{11}$ However, the real promise of using radionuclide imaging in future studies of the failing RV is probably achieved by combining targeted molecular imaging with rigorous quantification, preferably in a setting using multimodality imaging approaches. So far, this is relatively uncharted territory. There are some indications that aerobic glycolysis is an early phenomenon linked to RV functional deterioration, ${ }^{12}$ for which FDG-PET is the obvious tool for further research. ${ }^{11} \mathrm{C}$-acetate is the tracer of choice to study the impact of novel heart failure therapies on the link between RV work and oxidative metabolic activity. ${ }^{13-15}$

Additionally, non-invasive characterization of RV neuronal function holds promise for further understanding of what is needed to reverse RV failure. Here, there are currently two relevant tracers: ${ }^{123} \mathrm{I}-$ metaidobenzylguanidine (MIBG) used with SPECT, and ${ }^{11} \mathrm{C}$-meta-hydroxyephedrine (HED). Both are validated analogs of norepinephrine and have been used extensively in LV failure research, but RV-related data are only just emerging. ${ }^{16}$

In this issue, Ahmadi et al. present findings from a study using dynamic ${ }^{11} \mathrm{C}$-acetate and ${ }^{11} \mathrm{C}$-HED PET combined with echocardiographic assessments in the right ventricle. The data were obtained from a previously published study in a cohort of patients $(n=33)$ with reduced LVEF in the context of sleep apnea. ${ }^{17}$ PET data were analyzed with the software FlowQuant, 
refined over many years in the same institution. In addition to the standard LV polar maps, the software also maps the RV.

Ten subjects were diagnosed with RV dysfunction. Although the sample was relatively small, there were significant associations of $\mathrm{RV}-\mathrm{MVO}_{2}$, derived from ${ }^{11} \mathrm{C}$ acetate data, and echocardiographic function, and increased $\mathrm{RV}-\mathrm{MVO}_{2}$ predicted adverse events. ${ }^{11} \mathrm{C}$ HED uptake (measured both as SUV, normalized to body weight, and as a retention index, normalized to the arterial input function integral) was significantly lowered in RV dysfunction.

$\mathrm{RV}-\mathrm{MVO}_{2}$ was calculated by measuring kmono, the monoexponential washout rate of ${ }^{11} \mathrm{C}$-acetate metabolites from the wall. Washout rates are relatively insensitive to partial volume effects, which is why kmono values tend to be similar regardless of scanner resolution and can be used even in the thin RV wall.

On the other hand, HED SUV and retention index are uptake values that were basically measured from a static image obtained 30-40 minutes after injection. Uptake values are highly affected by partial volume effects, resulting in falsely low signal in thin walls and with a further reduction of signal proportional to the amplitude of motion. With this confounder in mind, the association of low HED uptake with RV failure found by Ahmadi et al. might actually be even more pronounced than what their numbers state. The initial consequence of pressure overload is development of hypertrophy, which reduces partial volume effect and increases signal recovery.

To compensate for variable wall thickness, the authors applied a correction for incomplete wall signal recovery using a fractional blood volume estimated from the ${ }^{11} \mathrm{C}$-acetate scans (corrected uptake $=$ uptake $/(1-$ blood volume fraction). However, this maneuver leaves the uptake value uncorrected for the partial volume effect induced by overlapping lung tissue.

Scanner resolution and reconstruction algorithms improve continuously with both SPECT and PET, which will lead to increasingly exquisite depictions of biology even in the right ventricular wall. Simultaneously, there is an ever-growing amount of tracers that might be relevant for research into heart failure. Combining these factors, it is a low-risk bet to assume that nuclear cardiology will continue to provide further insights into RV function and targeted restorative therapies in the years to come.

\section{Disclosure}

Jens Sörensen has no conflicts of interest to declare.

\section{References}

1. Fontan F, Baudet E. Surgical repair of tricuspid atresia Thorax 1971;26(3):240-8.

2. Sanz J, Sánchez-Quintana D, Bossone E, Bogaard HJ, Naeije R. Anatomy, function, and dysfunction of the right ventricle: jACC state-of-the-art review. J Am Coll Cardiol 2019;73(12):1463-82.

3. Guazzi M, Naeije R. Pulmonary hypertension in heart failure: pathophysiology, pathobiology, and emerging clinical perspectives. J Am Coll Cardiol 2017;69(13):1718-34.

4. Lahm T, Douglas IS, Archer SL, Bogaard HJ, Chesler NC, Haddad $\mathrm{F}$, et al. Assessment of right ventricular function in the research setting: knowledge gaps and pathways forward. An Official American Thoracic Society Research statement. Am J Respir Crit Care Med 2018;198(4):e15-43.

5. Mannting F, Zabrodina YV, Dass C. Significance of increased right ventricular uptake on $99 \mathrm{mTc}$-sestamibi SPECT in patients with coronary artery disease. J Nucl Med 1999;40(6):889-94.

6. Frille A, Steinhoff KG, Hesse S, Grachtrup S, Wald A, Wirtz H, et al. Thoracic $[18 \mathrm{~F}]$ fluorodeoxyglucose uptake measured by positron emission tomography/computed tomography in pulmonary hypertension. Medicine 2016;95(25):e3976.

7. Li W, Wang L, Xiong C-M, Yang T, Zhang Y, Gu Q, et al. The prognostic value of $18 \mathrm{~F}-\mathrm{FDG}$ uptake ratio between the right and left ventricles in idiopathic pulmonary arterial hypertension. Clin Nucl Med 2015;40(11):859-63.

8. Oikawa M, Kagaya Y, Otani H, Sakuma M, Demachi J, Suzuki J, et al. Increased [18F]fluorodeoxyglucose accumulation in right ventricular free wall in patients with pulmonary hypertension and the effect of epoprostenol. J Am Coll Cardiol 2005;45(11):184955.

9. Dorbala S, Ananthasubramaniam K, Armstrong IS, Chareonthaitawee P, DePuey EG, Einstein AJ, et al. Single Photon Emission Computed Tomography (SPECT) Myocardial Perfusion Imaging Guidelines: Instrumentation, Acquisition, Processing, and Interpretation. J Nucl Cardiol 2018;25(5):1784-846.

10. Dilsizian V, Bacharach SL, Beanlands RS, Bergmann SR, Delbeke $\mathrm{D}$, Dorbala S, et al. ASNC imaging guidelines/SNMMI procedure standard for positron emission tomography (PET) nuclear cardiology procedures. J Nucl Cardiol 2016;23(5):1187-226.

11. Ohira H, Beanlands RS, Davies RA, Mielniczuk L. The role of nuclear imaging in pulmonary hypertension. J Nucl Cardiol 2015;22(1):141-57.

12. Ryan John J, Archer Stephen L. The Right Ventricle in Pulmonary Arterial Hypertension. Circ Res 2014;115(1):176-88.

13. Ukkonen H, Saraste M, Akkila J, Knuuti J, Karanko M, Iida H, et al. Myocardial efficiency during levosimendan infusion in congestive heart failure. Clin Pharmacol Ther 2000;68(5):522-31.

14. Knuuti J, Sundell J, Naum A, Engblom E, Koistinen J, Ylitalo A, et al. Assessment of right ventricular oxidative metabolism by PET in patients with idiopathic dilated cardiomyopathy undergoing cardiac resynchronization therapy. Eur J Nucl Med Mol Imaging 2004;31(12):1592-8.

15. Timmer SAJ, Knaapen P, Germans T, Lubberink M, Dijkmans PA, Vonk-Noordegraaf A, et al. Right ventricular energetics in patients with hypertrophic cardiomyopathy and the effect of alcohol septal ablation. J Card Fail 2011;17(10):827-31.

16. Gimelli A, Pugliese NR, Bertasi M, Airò E, Bauleo C, Formichi B, et al. Cardio-pulmonary involvement in pulmonary arterial hypertension: A perfusion and innervation scintigraphic evaluation. J Nucl Cardiol 2019. https://doi.org/10.1007/s12350-01901689-w.

17. Hall AB, Ziadi MC, Leech JA, Chen S-Y, Burwash IG, Renaud J, et al. Effects of short-term continuous positive airway pressure on 
myocardial sympathetic nerve function and energetics in patients with heart failure and obstructive sleep apnea: a randomized study. Circulation 2014;130(11):892-901.
Publisher's Note Springer Nature remains neutral with regard to jurisdictional claims in published maps and institutional affiliations. 